\title{
SOBRE A VELHICE INSTITUCIONALIZADA: UM DESAFIO PARA A EDUCAÇÃO FÍSICA
}

\author{
Alessandro Rovigatti do Prado \\ Universidade de São Paulo, São áulo, São Paulo, Brasil \\ Yara Maria de Carvalho \\ Universidade de São Paulo, São áulo, São Paulo, Brasil
}

\begin{abstract}
Resumo
Neste ensaio discorremos a respeito da velhice e do seu processo de institucionalização asilar, analisando a construção da identidade social do idoso e sua segregação em uma sociedade "formada e educada" para o trabalho e pelo consumo. Ao se ver destituído de sua função na lógica do capital, o indivíduo perde também as possibilidades de ressignificação de sua própria vida. Nesse sentido, entendemos como fundamental problematizar essas questões no campo acadêmico denominado Educação Física, considerando que ele diz respeito a uma prática social, ou uma prática pedagógica, que pode promover encontros visando ações compartilhadas, construção de vínculos e, sobretudo, produção de saúde e, em última instância, de vida.
\end{abstract}

Palavras chave: Velhice. Idoso. Educação Física. Produção de Saúde.

\section{Introdução}

Ninguém escapa da transformação natural conduzida pelo tempo, das sutilezas com as quais as células modificam traços que vão tomando forma, marcando a pele e desenhando riscos que se alinham como uma estrada com destino certeiro, a morte. Pensar a velhice e suas relações com o mundo vai além de ser solidário com os idosos, é, sobretudo, refletir sobre nosso próprio acolhimento e assistencialismo no futuro. "O velho não tem armas. Nós temos que lutar por ele." (BOSI, 1994, p. 18). É dentro dessa premissa que este ensaio teórico se fundamenta, visando contribuir para o pensamento sobre algumas relações e condutas acerca da velhice.

Neste texto trataremos do idoso por meio de um ponto de vista histórico-social, associando o percurso de sua identidade social com as preocupações e cuidados que surgem quando seus corpos passam a ser "indomáveis"

Pensar a Prática, Goiânia, v. 17, n. 2, p. 593-605, jan./mar. 2014 593 
diante das exigências de um mundo educado pelo o consumo e para o trabalho.

No primeiro tópico, portanto, atentaremos para um breve recorte histórico que repercutiu no processo de segregação etária da vida. Na sequência, pensando em um contexto paralelo a este processo de segregação, abordaremos o assistencialismo social, focalizando a temática do asilo. No terceiro tópico defenderemos a possibilidade do não domínio, ou seja, a "indomabilidade" sobre o corpo do idoso, considerando uma realidade propulsora para este fenômeno. Por fim, nas considerações finais, encerraremos o texto com algumas reflexões, abrindo possibilidades para se "pensar a prática" no contexto do asilo.

\section{A segregação etária na velhice}

O surgimento de uma identidade social dialoga com o processo de segregação etária. No caso das identidades relacionadas à velhice, este processo teve influências de mobilizações sociais que, diante de certas condições de vida da época que corresponde ao século XIX, exigiam políticas públicas frente às dificuldades locais vivenciadas (PEIXOTO, 1998).

Ao longo do século XIX e principalmente no século XX, a ideologia industrial foi se firmando nas bases da cultura brasileira. Dos reflexos desse processo de industrialização, podemos citar a rápida e intensa urbanização, modificações nas relações comerciais, aperfeiçoamento das estruturas e dos meios de transporte, crescimento demográfico, mudanças nas relações de poder, o aumento da desigualdade social, entre outros (AZEVEDO, 2010).

Com a cultura industrial e suas transformações econômicas, que abriram portas para investimentos em vários setores, a estrutura social passou a se modificar, influenciando gradativamente, a partir deste mesmo século, as diferenças de funções, hábitos e espaços relacionados a cada grupo etário, segmentando o curso da vida em estágios formais.

Isso ocorreu de tal forma que no século XX já se reconhecia um determinado padrão de condutas, crenças, ideais e preferências presentes em cada grupo etário (HAREVEN, 1995). Silva (2008) ressalta que esse processo de organização das etapas da vida e de criação de identidades etárias no Brasil se fez presente nas várias esferas da vida social, como por exemplo no caso do idoso - no espaço familiar (figura dos avós), no âmbito do trabalho (políticas de aposentadoria), nos domínios do Estado (criação de benefícios ao idoso) e no mercado de consumo (medicamentos, programas de lazer e serviços destinados à terceira idade, entre vários outros).

O discurso sobre a senescência, ligada ao processo de degenerações, perdas e declínios de funções biológicas, junto com uma visão mais humani-

Pensar a Prática, Goiânia, v. 17, n. 2, p. 593-605, jan./mar. 2014 594 
tária do sujeito velho, aliando-se a questões psicossociais da velhice, foram ganhando destaques principalmente ao longo do século $\mathrm{XX}$, influenciando estereótipos e modos de relação com o idoso. Na segunda metade deste século, a velhice passou a ser "[...] objeto do discurso de legisladores sociais, dando ensejo à criação de instituições específicas, como as caixas de aposentadoria para a velhice, e à especialização progressiva de determinados hospícios em asilos para velhos" (SILVA, 2008, p. 159).

Além da segregação entre os períodos da vida, existe também a segregação dentro da própria faixa etária, isto é, no caso do idoso, observa-se o aparecimento de termos que fazem referência ao sujeito, como 'velho', 'idoso', 'terceira idade' e etc. Estes termos podem ser um indicativo da heterogeneidade dentro desta faixa etária, além de fazerem referência principalmente com relação ao estilo de vida e condição socioeconômica (MARQUES, 2004).

A segregação etária é apenas um elemento dentro da história que nos oferece respaldo para compreender a identidade do sujeito em questão. Outro elemento, que também merece atenção, é a questão das práticas assistenciais ao idoso.

\section{O assistencialismo social}

Groisman (1999) recorre à história de um asilo, Asilo São Luiz para Velhice Desamparada, na cidade do Rio de Janeiro, então capital política e econômica do Brasil no final do século XIX. A separação da velhice de outras categorias de assistências sociais marcou este período e o autor supracitado busca elucidar a origem da institucionalização da velhice através de acontecimentos e mobilizações da sociedade, da mídia e de órgãos políticos. Apesar de retratar a história de um local específico, o autor aborda diversos elementos que motivaram o fenômeno na institucionalização no Brasil. Ele aponta que a instituição em questão surgiu como referência para a época e que seu crescimento, ligado ao surgimento de apoios e suportes de várias naturezas, inclusive estatal, estavam ligados às representações sociais da velhice.

A história da assistência social, pelo menos no Brasil, possui origem atrelada com base na caridade, filantropia e solidariedade religiosa (RAMOS, 2009). Retornando ao século XIX, podemos identificar dois momentos, de acordo com Groisman (1999): na sua primeira metade, fazer caridade era um ato de fé, por isso a comunidade cristã foi pioneira nessas práticas de assistência social que ainda não eram alvo de políticas sistematizadas, apesar da preocupação social com os indigentes, inválidos e pobres. Em contraposição, na segunda metade do século XIX, com a abolição da escravidão,

Pensar a Prática, Goiânia, v. 17, n. 2, p. 593-605, jan./mar. 2014 595 
veio à tona a necessidade de transformar 'pobres livres' em trabalhadores assalariados, alterando as condutas e procedimentos em relação a essa população (pobres livres), tudo isso motivado pelo amadurecimento da filantropia e da medicina social.

Neste momento, a filantropia-higiênica e as novas concepções pedagógico-sanitárias começaram a influenciar os modelos de assistência social, inclusive para os idosos. Segundo Mestriner (2001), a filantropia-higiênica se configura como marco no surgimento de orfanatos, asilos, hospícios, reformatórios, entre outros, e foi uma política responsável pela instalação de ambientes de acolhimento aos desamparados, independente de sua causa ou natureza. Essa abordagem significou um avanço no tratamento social frente aos primeiros hospitais (até mesmo a cadeia pública), que atendiam a todos.

Portanto, no século XIX, o assistencialismo social e o desenvolvimento de ações e políticas de assistência à pobreza influenciaram o surgimento de asilos com espaço específico para idosos. Groisman (1999) destaca a atenção da sociedade frente ao gerenciamento dessas assistências, pois se de um lado estava quem precisava de amparo, do outro havia indivíduos com condições para exercer o trabalho que se aproveitavam destas políticas sociais.

Devido à origem atrelada às práticas de assistência social, as instituições que acolhem velhos surgiram de asilos, inicialmente a serviço de abrigar uma população geral e miserável - dentre os necessitados estavam mendigos, velhos, indigentes, crianças órfãs, entre outros. Neste período, a velhice passava por um momento de reconhecimento de suas necessidades, sendo desvinculada do cuidado e acolhimento junto à população miserável, e ganhando espaço próprio.

De acordo com Christophe e Camarano (2010), os preconceitos relacionados à institucionalização asilar dos idosos são decorrentes, em grande parte, de sua origem assistencialista e também da má qualidade de serviços de parte das instituições. Além disso, o medo da morte e a proximidade com a finitude da vida também fomentam preconceitos com relação às instituições, tendo em vista que são espaços destinados a pessoas em seu último estágio na vida: “(...) o ingresso em um asilo não vem acompanhado de um projeto de retorno à comunidade e à família." (CHRISTOPHE E CAMARANO, 2010, p.153).

\section{A "indomabilidade" do corpo velho}

A mobilização por parte da sociedade, que contribuiu para que o idoso ganhasse espaço próprio dentro de práticas de assistência social, faz pensar no reflexo da imagem do corpo velho para as pessoas que direta ou indi-

Pensar a Prática, Goiânia, v. 17, n. 2, p. 593-605, jan./mar. 2014 596 
retamente convivem com idosos. Muito além disso, instiga a refletir sobre a lógica da ideologia de dominação em massa, que gerencia o poder sobre a vida através da biopolítica no exercício do biopoder. Essa forma de considerar a realidade é destaque no pensamento foucaultiano que, de acordo com Assman et al (2007), trata-se de um controle que atua sobre a vida do sujeito, manipulando, de certa forma, sua maneira de ser.

Esse processo tem na população seu objeto e na estatística e na biomedicina sua ancoragem de saber. O poder sobre a vida se instala por meio da instituição de diversos dispositivos de caráter sexual, pedagógico, clínico e penal, permitindo a capilarização das possibilidades de intervenção do Estado sobre a vida da população (grifos do autor) (ASSMAN et al, 2007, p. 1).

O exercício do biopoder na cultura ocidental, somado à ideologia capitalista, atribui negatividades aos corpos inúteis para a serventia do ofício e desloca a atenção para a imagem jovem de ser, à qual se atribui virilidade e versatilidade, condições ótimas para exercer o trabalho (SANTOS \& DAMICO, 2009).

O velho representa uma ameaça à ordem do sistema, posto que não é mais produtivo ao capital e está em descompasso com o imperativo do "tempo é dinheiro". E por isso ele é relegado, por possuir características muitas vezes opostas às exigidas pelo sistema, que não o permitem mais ser tão apto ao trabalho, como era quando jovem (SANTOS \& DAMICO, 2009, p. 6).

Quando um corpo se esgota para as funções que lhe seriam atribuídas dentro da lógica do capitalismo, ele passa a ser indomável, torna-se um corpo selvagem do ponto de vista da ideologia hegemônica e por isso representa uma ameaça ao sistema. Sem função, seu destino muitas vezes passa a ser o asilo. Deste modo, com pouca chance de ser novamente dominado, as possibilidades de vida que a cultura ocidental oportuniza se esgotam. Naturalmente sua autonomia e disposição para a busca por novas formas de viver tornam-se cada vez mais restritas, tanto pelas dificuldades sociais inerentes a esta faixa etária, quanto pelos declínios da capacidade funcional. Para termos uma noção do perfil do idoso que frequenta um asilo, ilustraremos isso com alguns trabalhos nos próximos três parágrafos.

Ferreira \& Simões (2011), em pesquisa realizada em dois asilos (um particular e outro público), relataram, através de análise dos discursos, o 
sentimento de tristeza relacionado com a exclusão social, principalmente a exclusão pela família. A percepção das restrições funcionais foi encarada pelos idosos entrevistados como algo natural. Notou-se também o predomínio de percepções negativas em relação ao próprio corpo e ao envelhecimento. As autoras também entrevistaram os funcionários de ambas as instituições, que convergiram opinião ao se referirem aos idosos como sendo carentes, isto é, necessitando de afeto, principalmente familiar. Outros pontos destacados pelos funcionários foram a exclusão, atrelada à inutilidade, e a dependência para execução de tarefas da vida diária.

Um levantamento realizado no Brasil apontou possíveis motivos para o asilamento (BORN \& BOECHAT, 2006). Os autores citam problemas relacionados à capacidade funcional, o diagnóstico médico de doenças (cardíacas, renais, respiratórias e etc.), a depressão, a demência, a alta hospitalar recente, a incontinência e o isolamento social. Apesar de parecer recorrente o termo de exclusão social para caracterizar essas instituições frente ao asilamento do idoso, os autores deste trabalho revelaram que grande parte dos idosos não estava interessada em novas amizades, tornando-se personalidades fechadas para outros contatos sociais. Portanto, muitas vezes a única opção que resta ao sujeito é se submeter à instituição e a toda a mudança de rotina, isso sem contar os problemas pessoais e funcionais, que, juntos, implicam na alteração da personalidade, corroborando para o isolamento social e até mesmo para a instalação de um quadro de depressão.

Herédia et al (2010) apresentaram dados a respeito de idosos asilados em Caxias do Sul. Quanto aos motivos que levaram à institucionalização, destaque para a ausência de cuidador e para o fato de estarem morando sozinhos - com aproximadamente 34 e $25 \%$, respectivamente. Por motivo de doença ou por escolha do próprio idoso, são opções que apareceram intermediárias - com aproximadamente 9 e $8 \%$, respectivamente. Quando questionados sobre como gostariam de ocupar o tempo livre, as quatro opções mais escolhidas foram: fazer trabalhos artesanais e domésticos $(27,47 \%)$, trabalhar $(17,58 \%)$, não quer se ocupar $(15,38 \%)$ e não pode se ocupar (12,09\%). É interessante notar que a opção "conversar" foi pouco escolhida, com aproximadamente $2 \%$, o que nos possibilita pensar em um indicativo de comportamento fechado a contatos sociais por parte desses indivíduos.

Esse breve relato do perfil de idosos institucionalizados revela que as portas se fecharam e a possibilidade de o próprio sujeito administrar sua vida fica restrita aos tratos da instituição. Necessitando de cuidados e com pequenas possibilidades de ser dominado pela cultura do capital, este idoso perde sua função nesta sociedade.

Pensar a Prática, Goiânia, v. 17, n. 2, p. 593-605, jan./mar. 2014 598 
Baptista (2012) afirma que a disciplina do corpo ocorre em compasso com os objetivos político-sociais estabelecidos, sendo cultuado um corpo jovem, magro e com definição muscular. Porém, "um dos problemas relacionados a isso é o fato de as pessoas, forçosamente, envelhecerem e perderem paulatinamente essas características" (BAPTISTA, 2012, p. 1072). Junto a isso, a indústria cultural investe em estratégias para mistificar a velhice, criando ilusões acerca do corpo jovem, tornando-o imortalizado através de procedimentos estéticos, só que ela “(...) promete, mas não cumpre, aponta para a sublimação, mas reprime pela disciplina." (BAPTISTA, 2012, p. 1072). E quando o corpo se torna incapaz de ser domesticado nos moldes do trabalho, o sujeito é muitas vezes deslocado para fora do sistema.

As sociabilidades criadas pela cultura industrial e sustentadas pela biopolítica, de certa forma, repulsam os sujeitos inaptos para prosseguirem com a continuidade do poder hegemônico. O processo de dominação em massa ocorre principalmente através de mudanças internas dentro do aparetho do Estado requeridas pelo industrialismo. "Assim, cada Estado procura criar, difundir e manter formas específicas de sociabilidade conforme o projeto societário do bloco no poder, assumindo uma função claramente educativa" (MELO, 2012, p. 452).

Isso implica em transformações a nível de compreensão do mundo e reflete em atitudes, condutas e comportamentos diante dos vários temas presentes na contemporaneidade, como por exemplo, sexualidade, estética, saúde e arte, disseminando através da educação, cultura e lazer, os ideais societários (MELO, 2012). Dessa maneira, muitas formas de ser são estigmatizadas, ademais, a exclusão do círculo social, muitas vezes inclusive pela própria família, contribui para que muitos idosos naufraguem em um oceano de impossibilidades, pois eles não podem sair, não têm companhia, têm poucas opções de lazer e entretenimento, ficam submetidos às normas da instituição, dentre outros fatores.

Diante deste panorama pleno de vicissitudes morais e éticas advindas das diferentes formas de representações da vida e sobre ela, em específico, aqui, acerca da velhice, podemos ressaltar, através da leitura feita, que o corpo do idoso encontra-se indomável. O desafio, portanto, para a pedagogia sobre o corpo velho, se não fossem atribuídas a ela as funções capitalistas advindas do esporte e do processo de disciplina do corpo para o trabalho, seria aderir às práticas corporais que oportunizassem novos horizontes dentro desta etapa da vida. Aqui, poderíamos pensar, por exemplo, além de domesticar o idoso para a vida que se finda, de subjugar a morte para os domínios do idoso. 


\section{Considerações Finais: "pensar a prática" sobre o corpo velho}

Nada é mais insuportável para o homem do que estar em pleno repouso, sem paixões, sem afazeres, sem divertimento, sem aplicação. Ele sente todo seu nada, seu abandono, sua insuficiência, sua dependência, sua impotência, seu vazio. Imediatamente nascerão do fundo de sua alma o tédio, o negrume, a tristeza, a mágoa, o despeito, o desespero (PASCAL, 2001, p. 268).

A partir dessa breve leitura acerca do idoso, e levando em conta o processo de afirmação das políticas assistenciais, vamos tecer algumas considerações enfatizando a instituição asilar em função de algumas possibilidades a serem abertas e pensadas.

Camarano (2002) apresenta uma contribuição demográfica para o entendimento do processo de envelhecimento da população brasileira e aponta que há um crescimento acelerado da população idosa com relação aos outros grupos etários. Junto a isso, cada vez mais pessoas estão sobrevivendo às idades elevadas, o que indica que a demanda para o cuidado e o acolhimento das pessoas idosas deve aumentar, tendo em vista a dependência e a perda de autonomia que tendem a ser um agravo com o avançar da idade (CAMARANO, 2010). Por isso, o envelhecimento da população brasileira é um elemento desafiador para a elaboração de políticas públicas de saúde, inclusive, segundo Tomasini \& Alves (2006), pelo crescente número de idosos acima de 70 e 80 anos, que aponta para um aumento na demanda por instituições asilares para as próximas décadas.

Freire Jr \& Tavares (2006) destacam a importância de se desenvolver pesquisas e de se pensar em ações de promoção da saúde para idosos asilados, apesar da complexidade da aplicação de políticas públicas nesses contextos. A Educação Física aparece como um campo de produção de conhecimento, formação e intervenção em potencial para o desenvolvimento destas e de outras alternativas, sendo necessário, porém, compreender o que vem sendo realizado pelos profissionais específicos, haja vista a carência de relatos e iniciativas neste contexto.

A pesquisa aparece com um papel de extrema importância, à medida que pode contribuir para revelar, documentar, reconhecer, avaliar, criticar, aperfeiçoar, valorizar ou propor novas perspectivas para as instituições asilares. Araújo et al (2010), que realizaram uma busca eletrônica em sites da Biblioteca Virtual de Saúde por trabalhos científicos entre 2000 e 2009 com os termos "idoso", "asilos para idosos" e "instituição de longa permanência para idosos", encontraram 653, 66 e 72 publicações, respectivamente, para

Pensar a Prática, Goiânia, v. 17, n. 2, p. 593-605, jan./mar. 2014 600 
os termos citados. Essas informações servem de indicativo para se ter uma noção da escassez de trabalhos e da necessidade de ampliar o campo de visão sobre o idoso asilado.

Frente a isso, uma possibilidade seria investir em ações que complementem o serviço nas instituições, facilitando a busca por soluções de acolhimento e amenizando os principais fatores inerentes ao processo de asilamento que afetam os indivíduos, como evidenciado na literatura: depressão, solidão e sedentarismo, como alguns exemplos. Outra estratégia seria implementar políticas públicas de conscientização sobre a importância do cuidado ao idoso dependente, pois, se a família não tem condições, pelo menos orientações e indicações de serviços poderiam ser disponibilizados à comunidade.

Investir na formação e educação permanente dos profissionais inseridos no contexto asilar e em informação e educação para a comunidade frente à realidade da velhice, bem como conhecer o trabalho dos profissionais de saúde diante do idoso desamparado, são ações que poderão contribuir também na proposição de processos de trabalho e modelos de intervenção. Entendemos que é fundamental intervir no sentido de ampliar a relação entre a assistência, o serviço de saúde e a comunidade, de tal forma a agregar valores e garantir o acesso aos equipamentos e serviços.

A negação da velhice é a tônica da sociedade ocidental contemporânea que esconde o furto de uma identidade social. O medo de ser assaltado por essa cultura e ter a identidade saqueada, gera mercado. O medo de envelhecer cria possibilidades de consumo e, ao mesmo tempo, colabora para reforçar o estigma da velhice.

Acreditamos que a velhice aspira por muitas possibilidades de existência e a luta deve ser contra a banalização de ser velho. A morte - agregando aqui diferentes tipos de morte, não somente a biológica - diz respeito à ruptura da vida, momento em que deixamos de perceber, sentir e realizar nossas experiências. Precisamos de saúde e de viver para diferentes experiências.

\title{
ABOUT THE INSTITUTIONALIZATION OF THE OLD AGE: A CHAL- LENGE FOR PHYSICAL EDUCATION
}

\begin{abstract}
In this essay we discussed about the old age and its process of institutionalization analyzing the construction of the social identity of the elderly and their segregation in a society educated for work and by consumption. When they find themselves deprived of their function in a society based on capital, the elderly also lose the possibilities of re-signifying their own life. In this sense, we understand that it is fundamental to problematize the questions in the academic field of Physical Education
\end{abstract}

Pensar a Prática, Goiânia, v. 17, n. 2, p. 593-605, jan./mar. 2014 601 
considering that it concerns to a social or a pedagogical practice, that could promote meetings with the purpose of shared actions, forming bondings and, above all, producing health and life.

Keywords: Old Age. Physical Education. Produce of Health.

\section{ACERCA DE LA INSTITUCIONALIZACIÓN DE LA VEJEZ: UM RETO PARA LA EDUCACIÓN FÍSICA}

\section{Resumen}

Este ensayo discurre a respecto de la vejez y de su proceso de institucionalización analizando la construcción de la identidad social de lo individuo vejez y su segregación en una sociedad "formada y educada" para lo trabajo y pelo consumo. A o se ver destituido de su función en la lógica de lo capital, lo individuo pierde también posibilidades de res significación de su propia vida. En este sentido, entendemos como fundamental problematizar esas cuestiones en lo campo académico denominado Educación Física considerando que ele comprende una práctica social, o una práctica pedagógica, que pode promover encuentros visando acciones compartidas, construcción de vínculos y, sobretodo, producción de salud y de vida.

Palabras-claves: Edad Viejo. Educación Física. Producción de Salud.

\section{Referências}

ASSMANN, S. J.; PICH, S.; GOMES, I. M.; VAZ, A. F. Corpo e biopolítica: poder sobre a vida e poder da vida. In: XV Congresso Brasileiro de Ciências do Esporte [e] II Congresso Internacional de Ciências do Esporte / Colégio Brasileiro de Ciências do Esporte, 2007, Recife/Olinda. Anais do XV Congresso Brasileiro de Ciências do Esporte [e] II Congresso Internacional de Ciências do Esporte / Colégio Brasileiro de Ciências do Esporte. Goiânia: CBCE, p. 1-9, 2007.

ARAÚJO, C. L. O.; SOUZA, L. A.; FARO, A. C. M. Trajetória das instituições de longa permanência para idosos no Brasil. História da Enfermagem - Revista Eletrônica, v.1, n.2, p.250-262, 2010.

AZEVEDO, E. B. Patrimônio industrial no Brasil. Revista Eletrônica de Arquitetura e Urbanismo, n.3, 2010.

Baptista, T. J. R. Da disciplina do corpo e educação física: notas para entender algumas relações sociais. Revista Pensar a Prática, v. 15, n.4, p. 8211113, out./dez. 2012. 
BORN, T.; BOECHAT, N. S. A qualidade dos cuidados ao idoso Institucionalizado. In: FREITAS, E. V. Tratado de Geriatria e Gerontologia. Rio de Janeiro: Guanabara Koogan, p. 768-77, 2006.

BOSSI, E. Memória e sociedade: lembrança de velhos. 3. ed. São Paulo: Companhia das Letras, 1994.

CAMARANO, Ana Amélia. Envelhecimento da população brasileira: uma contribuição demográfica. Rio de Janeiro: IPEA, n.858, p. 1-26, 2002.

CAMARANO, A. A. Cuidados de Longa Duração para a população Idosa: um novo risco social a ser assumido? In: CAMARANO, A. A (org.). Cuidados de Longa Duração para a população Idosa: um novo risco social a ser assumido? Rio de Janeiro: IPEA, p. 337-349, 2010.

CRISTOPHE, M.; CAMARANO, A. A. Dos asilos às Instituições de Longa Permanência: uma história de mitos e preconceitos. In: CAMARANO, A. A (org.). Cuidados de Longa Duração para a população Idosa: um novo risco social a ser assumido? Rio de Janeiro: IPEA, p. 145-162, 2010.

FERREIRA, L.; SIMÕES, R. Idoso Asilado: Qual sua imagem? São Paulo: Fontoura, 2011.

FREIRE JR, R. C.; TAVARES, M. F. L. A promoção da saúde nas instituições de longa permanência: uma reflexão sobre o processo de envelhecimento no Brasil. Revista Brasileira de Geriatria e Gerontologia, v.9, n.1 p.83-92, 2006.

GROISMAN, D. Asilos de Velhos: passado e presente. Estudos Interdisciplinares Sobre o Envelhecimento, v.2, p. 67-87, 1999.

HAREVEN, T. Changing images of aging and the social construction of the life course. In: Featherstone, M.; Wernick, A. (Org.). Images of aging: cultural representations of later life. London: Routledge, p. 119-135, 1995.

HERÉDIA, V. B. M.; CORTELLETTI, I. A.; CASARA, M. B. Institucionalização do idoso: identidade e realidade. In: CORTELETTI, I. A.; CASARA, M. B.; HERÉDIA, V. B. M. (Orgs.). Idoso asilado: um estudo gerontológico. 2. ed. Porto Alegre: Edipucrs, p.15-62, 2010. 
MARQUES, A. M. Velho/Idoso: construindo o sujeito da terceira idade. Revista Esboços UFSC, v.11, n.11, p.65-71, 2004.

MELO, M. P. Gramsci, americanismo e fordismo e a educação do corpo. Revista Pensar a Prática, v. 15, n. 1, p. 447-464, abr./jun. 2012.

MESTRINER, M. L. O Estado entre a Filantropia e Assistência Social. São Paulo: Cortez, 2001.

PASCAL, B. Pensamentos. São Paulo: Martins Fontes, 2001.

PEIXOTO, C. Entre o estigma e a compaixão e os termos classificatórios: velho, velhote, idoso e terceira idade. In: BARROS, M. M. L. (Org.), Velhice ou terceira idade? Rio de Janeiro: Fundação Getúlio Vargas, p.15-17, 1998.

RAMOS, E. M. R. A Assistência Social no Brasil. Disponível em $<$ http://ww3.lfg.com.br/public_html/article.php?story=20090130165802896 $\&$ mode=print $>$. Publicado em 31 de janeiro de 2009. Acesso em: 09 de setembro de 2012.

SANTOS, F. C.; DAMICO, J. G. S. O mal-estar na velhice como construção social. Revista Pensar a Prática, v. 12, n. 1, p. 1-9, jan./abr. 2009.

SILVA, L. R. F. Da velhice à terceira idade: o percurso histórico das identidades atreladas ao processo de envelhecimento. Histórias, Ciências, Saúde, v.15, n.1, p. 155-168, 2008.

TOMASINI, S. L. V.; ALVES, S. Envelhecimento bem-sucedido e o ambiente das instituições de longa permanência. Revista Brasileira de Ciências do Envelhecimento Humano, v.4, n.1, p.88-102, 2006.

Recebido em: 09/05/2013

Revisado em: 15/12/2013

Aprovado em: 27/02/2014

Endereço para correspondência:

alessandro.rovigatti@gmail.com

Alessandro Rovigatti do Prado

Pensar a Prática, Goiânia, v. 17, n. 2, p. 593-605, jan./mar. 2014 604 
Universidade de São Paulo, Escola de Educação Física e Esporte, Departamento de Pedagogia do Movimento do Corpo Humano.

Rua Professor Melo Moraes 65

Cidade Universitária

05508-900 - Sao Paulo, SP - Brasil

Pensar a Prática, Goiânia, v. 17, n. 2, p. 593-605, jan./mar. 2014 